\title{
Childcare providers' attitudes, knowledge, and practice related to developmental monitoring to promote early identification and referral
}

Gail Chödrön ${ }^{a *}$, Kris Pizur-Barnekow ${ }^{\mathrm{b}}$, Stephan Viehweg ${ }^{\mathrm{c}}$, Alexandra PukAment $^{\mathrm{d}}$, and Brian Barger

${ }^{a}$ Waisman Center University Center for Excellence in Developmental Disabilities, University of Wisconsin-Madison, Madison, United States; ${ }^{b}$ Department of Occupational Science and Technology, University of Wisconsin-Milwaukee, Milwankee, United States; ${ }^{c}$ Riley Child Development Center, Indiana University, Indianapolis, United States; ${ }^{d}$ Nationwide Children's Hospital, Columbus, United States; ${ }^{e}$ School of Public Health, Georgia State University, Atlanta, United States

Waisman Center, 1500 Highland Avenue, University of Wisconsin-Madison, Madison, WI 53705, chodron@wisc.edu

This evaluation study was supported by funding from the Disability Research and Dissemination Center (DRDC) through its cooperative agreement number 5U01DD001007 from the Centers for Disease Control (CDC) and Prevention and by the Clinical and Translational Science Award (CTSA) program. Data analysis was supported in part through the NIH National Center for Advancing Translational Sciences (NCATS), grant UL1TR000427. The contents of this report are solely the responsibility of the authors and do not necessarily represent the official views of the DRDC, the CDC, or the $\mathrm{NIH}$.

\section{Notes on Contributors}

Gail Chödrön is the Wisconsin Maternal and Child Health Leadership Education in Neurodevelopmental and Related Disabilities program Training Director and Community Training and Technical Assistance Coordinator at the Waisman Center University Center for Excellence in Developmental Disabilities, University of Wisconsin-Madison. Her research and training efforts focus on early identification of developmental disabilities, community-based health promotion, and health equity in the context of disability.

This is the author's manuscript of the work published in final edited form as:

Chödrön, G., Pizur-Barnekow, K., Viehweg, S., Puk-Ament, A., \& Barger, B. (2019). Childcare providers' attitudes, knowledge, and practice related to developmental monitoring to promote early identification and referral. Early Child Development and Care. https://doi.org/10.1080/03004430.2019.1626373 
Kris Pizur-Barnekow is Associate Professor of Occupational Science \& Technology, University of Wisconsin-Milwaukee. Her research interests include early identification of developmental disorders in children and emotional disorders in mothers of children with special needs.

Stephan Viehweg is Assistant Research Professor of Pediatrics and Associate Director of the Riley Child Development Center, University of Indiana. His practice and research interest is in social-emotional development of infants and toddlers.

Alexandra Puk-Ament is a Postdoctoral Fellow in psychology at Nationwide Children's Hospital in Columbus, Ohio.

Brian Barger is Research Assistant Professor of Epidemiology and Biostatistics in the School of Public Health at Georgia State University's Center for Leadership in Disability. He conducts research on early identification of autism and other developmental disabilities informed by community systems and psychometric perspectives.

\section{ORCID}

Gail Chödrön https://orcid.org/0000-0002-0869-7936

Stephan Viehweg https://orcid.org/0000-0001-5361-5875

Brian Barger http://orcid.org/0000-0001-9403-1331 


\title{
Childcare providers' attitudes, knowledge, and practice related to developmental monitoring to promote early identification and referral
}

\begin{abstract}
Although intervening early can improve child and family outcomes when a child has a developmental disability, most children with developmental delays are not identified prior to school entry. Childcare professionals can play a key role in identifying delays early. The developmental monitoring attitudes, knowledge, and practice of childcare providers in the United States are described based on survey data. Findings indicate that childcare providers commonly monitor development but may do so in ways that are better suited to providing care than to identifying risk for developmental disability. Most providers identify early intervention/early childhood special education programs as a place to refer for developmental concerns, while not identifying referral to the doctor unless prompted to consider the doctor's role. Overall, these findings suggest childcare providers may be well poised to identify delays and make referrals early through developmental monitoring but need additional knowledge and tools to do so effectively.
\end{abstract}

Keywords: early identification; developmental monitoring; developmental delay; childcare

\section{Introduction}

Developmental delays and disabilities are common in young children, however, many children impacted are not identified prior to school entry (Guevera, et al., 2013; Macy, Marks \& Towle, 2014; Rosenberg, Zhang, \& Robinson, 2008). The CDC estimates that $15.1 \%$, or 1 in 6 children under 18, have a developmental disability of any type (Boyle et al, 2011). Interventions provided early when there is a developmental delay or disability can impact child as well as family outcomes (Bradshaw, Steiner, Gengoux, \& Koegel, 2015; Landa \& Kalb, 2012; Rogers et al, 2012; Rogers et al, 2019). Although not all children with a developmental disability will meet eligibility criteria for early intervention services through Part C (birth to age 3) or early childhood special education through Part B (starting at age 3) of the Individuals with Disabilities Education Act 
(IDEA), Rosenberg and colleagues conclude that up to $13 \%$ of children aged birth to 3 years old have developmental delays that would qualify them for Part C, based on common state eligibility criteria (Rosenberg, Zhang, \& Robinson, 2008). However, only $2-3 \%$ of children receive early Part $\mathrm{C}$ intervention services, and between 5-6\% receive early childhood special education services through IDEA Part B, Section 619 (Early Childhood Technical Assistance Center, n.d.; Macy, Marks \& Towle, 2014). While it's unclear how many young children with developmental disabilities access intervention through health care providers, data related to Part C/Part B enrolment suggest that many children with developmental disabilities may not be identified in time to access early interventions. Failure to identify children at risk for developmental disabilities limits access to the range of early intervention services that may improve child and family outcomes (Bailey et al, 2005; Bradshaw, Steiner, Gengoux, \& Koegel, 2015; French \& Kennedy, 2018; Hebbeler et al, 2007; Landa \& Kalb, 2012; Reichow, Hume, Barton, \& Boyd, 2018; Rogers et al, 2012). Because early detection of developmental delay in general, and of autism spectrum disorders (ASD) more specifically, is characterized by racial/ethnic and socio-economic disparities, lost opportunities for improved outcomes through early intervention disproportionately impact children and families already experiencing risk factors for poor developmental outcomes (Angell, Empey, \& Zuckerman, 2018; Durkin et al, 2017; Feinberg, Silverstein, Donahue, \& Bliss, 2011; Mandell et al, 2009).

For the past decade, there has been clear and consistent guidance indicating that primary care providers should conduct developmental surveillance and developmental screening for all young children at routine intervals, regardless of concern (Hagan, Shaw, \& Duncan, 2017). Nonetheless, only about a third of parents of U.S. children between the ages of 9 and 36 months report that their child received surveillance and 
screening from a health care provider during the previous year (Hirai, Kogan, Kandasamy, Reuland, \& Bethell, 2018). Childcare providers can also play an important role in early identification of developmental delays. In 2012, 12.5 million children age 0 to 4 years were in some form of childcare arrangement outside their own home (Branson, Virgil, \& Bingham, 2015), accounting for over half of U.S. children under the age of 5 years old (U.S. Census Bureau, 2018). Despite the role childcare providers can play, little is known about their current attitudes, knowledge, and practices related to early identification and referral processes. The purpose of the study reported here is to document the developmental monitoring attitudes, knowledge, and practices of childcare providers prior to completing training on this topic based on data collected through the 'Evaluation of Developmental Monitoring using Learn the Signs. Act Early. in Childcare Settings' study (Chödrön, et al, 2017). Findings on the impact of training are reported elsewhere (Chödrön, Barger, Pizur-Barnekow, Viehweg, \& Puk-Ament, 2019).

\section{Early Detection}

Some developmental disabilities are identified at birth, however, for others delays in reaching developmental milestones in the early years are the first indication of concern. The prototypical example is ASD, wherein children typically are not identified early enough to benefit from early interventions, despite the fact that most parents have developmental concerns well before their children turn three years of age (Baio et al., 2018) and most children display clear behavioural signs by the age of two (Constatino \& Marrus, 2017; Zwaigenbaum, et al., 2005). Research supports the contention that early detection of developmental disabilities is best supported when children universally receive developmental monitoring and developmental screening during early childhood using evidence-based tools and processes, regardless of concern (Barger, Rice, \& 
Roach, 2018a; Barger, Rice, Wolf, \& Roach, 2018b; Bright Futures Steering

Committee, 2006; Guerrero, Rodriguez, \& Flores, 2011; Guevara et al., 2013).

\section{Developmental Monitoring and Developmental Screening}

Recommendations for developmental monitoring and developmental screening in early childhood are drawn from guidance for health supervision of children published in Bright Futures (Hagan, Shaw, \& Duncan, 2017). While originating from guidance for paediatric primary care practice, community-based professionals who work with families of young children can also play a role in developmental monitoring and/or screening (Pizur-Barnekow et al, 2010). Bright Futures describes the importance of 'developmental surveillance' and developmental screening, where developmental surveillance includes 'eliciting and attending to the parents' concerns, maintaining a developmental history, making accurate and informed observations of the child, identifying the presence of risk and protective factors, periodically using screening tests, and documenting the process and findings' (Hagan, Shaw, \& Duncan, 2017: p. 78). Here, comprehensive developmental surveillance is inclusive of monitoring and screening activities. Developmental monitoring refers specifically to the surveillance activities of eliciting and discussing parents' concerns, 'making accurate and informed observations' of a child's development in the context of that child's developmental history, and documenting monitoring.

Whenever concerns arise based on developmental monitoring, developmental screening is indicated to obtain a more accurate assessment of risk for developmental disability (Hagan, Shaw, \& Duncan, 2017). Developmental screening is designed to utilize validated, standardized screening tools to reliably determine risk for developmental disability. Developmental screening with a validated tool typically requires formal training and purchase of materials that can be prohibitive for some early 
childhood professionals or programs, however, all professionals as well as parents can play an active role in developmental monitoring. Children for whom a developmental concern is identified should be referred to Part C or Part B services (depending on child age) and to the child's doctor for further assessment. Referral to both Part C/Part B and the child's doctor ensures the broadest access to developmental assessment, diagnosis/rule out of developmental disability, and interventions provided within and outside the health care system.

The knowledge base on the effectiveness of early identification processes has grown dramatically since Part C/Part B services were written into law, but continues to be limited in a number of different ways. Primarily, much more research has been conducted on developmental screening than developmental monitoring. This is partially due to a clear operational definition of developmental screening (i.e., presentation of developmental screening tool) and robust psychometric literature on screening instruments. Developmental monitoring, on the other hand, is not as clearly defined and is infrequently investigated. Furthermore, the literature on early identification activities is primarily focused on health care professionals. Additionally, despite strong literature on early identification tools, there is dearth of literature on the early identification process through which children are referred to Part C/Part B from community settings (Barger, Rice, Wolf, \& Simmons, 2018c). Thus, there is a need for more research on developmental monitoring among non-healthcare professionals from a community systems perspective to better understand the role of early childhood professionals, such as childcare providers, in early identification and referral to early intervention services.

While most of the current early identification literature is screener based in terms of psychometric evaluation or effectiveness of health care implementation leading to increased referrals, there is a growing literature indicating the importance of 
developmental monitoring. Importantly, Guevara et al. (2013) conducted a randomized control trial showing that developmental monitoring and screening received together leads to greater referrals to Part $\mathrm{C}$ early intervention services than monitoring alone. These findings are bolstered by recent analyses of the National Survey of Children's Health showing that children were more likely to be referred to and enrolled in Part C services when compared to children that received developmental monitoring alone, developmental screening alone, or neither developmental monitoring nor developmental screening (Barger et al., 2018b). While the use of developmental monitoring and screening in tandem is best practice, robust engagement in these early identification practices is not currently reported (Barger et al., 2018a; Barger et al., 2018b).

\section{Role of Childcare Providers in Early Detection}

Identification of children from birth through 21 who are eligible to receive services through Part C/Part B programs is mandated through Child Find (34 CFR 303.302, 20 U.S.C. 1412(a)(3)). Each state is responsible for identifying a reasonable plan for identification of eligible children. When children are not, or not yet, enrolled in the public school system, an informed referral network is particularly important for identifying children in the community. For children in care outside the home, childcare providers can play a key role in this informed referral network. The 2012 National Survey of Early Care \& Education (NSECE) estimates there are 3.8 million home-based and one million centre-based teachers and caregivers in the U.S. (National Survey of Early Care and Education Project Team, 2013). The survey documents a wide range in educational attainment, experience, and wages earned among these caregivers. Despite variation in educational attainment and experience, NSECE finds high commitment to caring for young children among respondents. Training childcare providers to conduct developmental monitoring and/or screening may improve overall rates of early 
detection and access to intervention prior to school entry.

Childcare provider engagement in developmental monitoring and/or screening is impacted not only by individual providers' attitudes, knowledge, and access to needed tools, but also by structures, policies, and processes that are beyond the control of the individual provider (Bloom, 2015). Although developmental screening is not a professional practice standard for childcare providers (see for example National Association for the Education of Young Children, 2009), there is support for developmental screening in childcare settings. For example, accreditation standards from the National Association for the Education of Young Children identify developmental screening using standardized, reliable, and valid tools that assess all domains of development as best practice for all childcare programs, regardless of whether they seek accreditation (National Association for the Education of Young Children, 2018), and resources specific to implementation of developmental screening by childcare providers is available (see for example Meisels \& Atkins-Burnett, 2005; U.S. Department of Health and Human Services \& U.S. Department of Education, 2014). Nonetheless, Boh and Johnson (2018) found that childcare providers frequently do not see universal screening as part of their professional role, which subsequently affects whether the childcare providers engage in universal screening practices. In a study of childcare providers' competence and confidence related to referring a child when there was a concern about developmental delay, Branson and Bingham (2017) found that 'prior experience working with children, knowledge and learning, and the availability of same aged peers' (p. 48) support childcare providers in early identification. Conversely, 'fear of talking with parents about concerns, lack of knowledge about referral systems, policies of the agency' (p. 48) and perceived lack of qualifications by the childcare provider hindered the childcare providers in this work. 
While there is little known about ECEP's attitudes towards screening, there is even less known about their attitudes toward developmental monitoring.

\section{'Learn the Signs. Act Early.'}

To improve developmental monitoring processes, the CDC developed and evaluated the Learn the Signs. Act Early. (LTSAE) campaign. LTSAE was designed to support parents' knowledge of developmental milestones and parent-professional conversations about child development, and to suggest what to do when there is a concern (Raspa et al, 2015). LTSAE resources currently include health education materials for families in print, online, and other formats, including a milestones tracking mobile app (available at no cost in Android and iPhone formats). Other LTSAE resources support implementation by professionals, including curriculum and tip sheets for developmental-behavioural paediatrics and for early care and education professionals (ECEPs). Additional resources, such as an online photo and video library of developmental milestones, are designed for both parents and professionals. Integration of LTSAE into a program involves using a subset of the available resources based on the appropriateness and feasibility of using specific LTSAE resources in that service context.

LTSAE materials are designed based on behaviour change theory and social marketing techniques (Raspa et al, 2015). Several evaluation studies of LTSAE materials have demonstrated an impact on public awareness and parent attitudes and practice (Burt, 2013; Graybill, Self-Brown, Lai, Vinoski, McGill, \& Crimmins, 2016; Patel, 2007; Westat, 2015; Crimmins, Graybill, \& Vinoski, 2013). Specifically, these studies have established that population-level awareness of ASD increased during the first two years of the LTSAE campaign and that parents had positive perceptions of LTSAE materials (Graybill et al, 2016; Raspa, et al., 2015; Patel, 2007; Westat, 2015). 
There is also evidence (based on parent self-report) that LTSAE materials impacted some parent outcomes, including increased tracking of developmental milestones in their own child(ren), increased comfort with and likelihood of following up with a professional as a result of developmental concern, and decreased concern about their own child's development (Campbell, Greenberg, Gallagher, Stoneburg \& Simmons, 2018; Graybill et al., 2016; Westat, 2015).

While these studies suggest that LTSAE materials may impact parental awareness, knowledge, and behaviour, far less is known about factors that impact LTSAE implementation. An exception is an evaluation study by Burt that analysed implementation of LTSAE in the context of everyday childcare operations (Burt, 2013). Burt's study of LTSAE implementation suggests that childcare environments characterized by support for provider-parent conversations about child development may enable effective developmental monitoring, while 'lack of credibility' (p. 17) and policies that impede provider-parent communication about concerns may hinder developmental monitoring in childcare settings. There is a need for research on developmental monitoring using LTSAE in community settings, including childcare.

\section{Methods}

\section{Study Design}

Findings reported here are derived from two arms of the 'Evaluation of Developmental Monitoring using Learn the Signs. Act Early. in Childcare Settings' study. (Chödrön, et

\footnotetext{
${ }^{1}$ Based on the UW-Madison Institutional Review Board (IRB) Office's QI/Program Evaluation Self-Certification Tool and a follow-up discussion with Education and Social/Behavioral
} 
al, 2017) designed to ascertain the feasibility and effectiveness of using LTSAE for developmental monitoring in childcare settings: Training-only and Training+TA. The design of each study arm and its measures was informed by focus groups with parents and childcare providers. The Training-only intervention was designed to demonstrate and evaluate the impact of individual provider training in the absence of technical assistance (TA), program-wide implementation, or system-level integration from a national sample. The Training+TA intervention was designed to demonstrate and evaluate the impact of training for individual providers followed by structured TA in the context of program-wide implementation with childcare programs in Wisconsin and Indiana. Participants in both arms of the study had little to no familiarity with LTSAE at the time of training. Data on baseline attitudes and practice related to developmental monitoring were collected through a pre-training survey.

\section{Study Participants}

Participation in the Training-only study arm was open to anyone who self-identified as an early care and education professional (ECEP) with internet access in the U.S. Participants were recruited by emails distributed through national, regional, and state early childhood organizations. Early childhood organizations were contacted by phone or email, provided with a description of the project, and invited to distribute the recruitment email through their ECEP email distribution list. Information describing the project and a link to the study webpage were included in emails sent to early care and education professionals. The study webpage included project information and links to

Science IRB staff, this project did not constitute research as defined under 45 CFR 46.102(d) and IRB review was not be required. 
study surveys. Once completed, the pre-survey redirected respondents to the training on a new browser page. Pre-training surveys were collected from August, 2015 through May, 2016. Participation in the Training+TA study arm was open to all ECEPs in 18 participating childcare programs. Programs were recruited from Wisconsin and Indiana to provide a sample that includes center-based, home-based, and childcare ministry programs in rural and urban areas (in Indiana, childcare ministry refers to childcares operated by a church/religious ministry that are registered but unregulated). ECEPs received a welcome letter describing the project and links to study surveys and training. Participating programs had the option of completing the survey in paper format. Training+TA surveys were completed from August, 2015 through January, 2016.

The dataset includes 489 responses to the pre-surveys (386 Training-only; 103 Training+TA). In order to analyse baseline practice of childcare providers, data are reported only for 384 participants who self-identified as childcare direct care providers, directors, owners, or other childcare administrators (regardless of additional roles identified). Participants excluded from analysis include those for whom the primary role could not be identified or was to provide training and TA to ECEPs. Table 1 describes included participants by type of program and current role in childcare.

\section{Measures}

For the purposes of this study, developmental monitoring in childcare settings was operationalized to include the following components:

1. Tracking the whole development (i.e., cognitive, communication, gross motor, fine motor, and social-emotional) of each child in ECEPs' care using an objective checklist

2. ECEPs talking with each child's parents about their child's development

3. ECEPs talking to parents when concerned about a child's development 
4. ECEPs connecting parents to outside programs or resources that can help when there is a concern about how their child is developing

Developmental monitoring practice was measured by asking respondents whether they track how the children in their care are progressing in terms of their whole development (component 1 ; yes/no response) and which forms of tracking they use (components 2 and 3; check-all-that-apply list of practice, with 'other' option allowing text response). ${ }^{2}$ Referral practice was measured based on demonstrated knowledge of where to refer a child if they were concerned about any aspect of their development (component 4; text response). Components of developmental monitoring and questions to measure practice were derived from discussion between evaluation team members and the Act Early project team at the Centers for Disease Control and Prevention.

Attitudes toward these aspects of developmental monitoring were measured based on the following questions: 'Do you believe it is important to keep track the whole development of every child in your care using an objective checklist or questionnaire?' (component 1; yes/no response); 'Do you see it as part of your role to suggest that parents talk to their child's doctor when there is a concern about how their child is developing?' (component 4; yes/no response); and 'When is it important for a child's family to consult with the child's doctor about how the child is developing?' (component 4; text response). These questions were derived from formative focus groups findings, which suggested that ECEPs may not view it as part of their

\footnotetext{
${ }^{2}$ Developmental monitoring methods list included: observe how children are developing by
} watching how they play; keep a portfolio to document each child's development by using photos, written observations, and/or video clips; talk to parents about what I am observing about their child's development; use a checklist of developmental milestones to document milestones reached; ask parents what they are observing about their child's development. 
professional role to monitor development using an objective checklist, and that ECEPs may have an unfavourable view of referring to the child's doctor because of perceptions that doctors don't understand child development and medicalize concerns (Chödrön, et al, 2017).

\section{Data Analysis}

Pre-survey data were matched to post- and delayed-surveys by a unique respondent identifier. Because program type and respondent role were included in more than one survey, the merged dataset was utilized to establish program type and respondent role when this data was missing from the pre-survey. Descriptive statistics were run on data from quantifiable measures. All text responses were coded. Text responses to the question 'How do you currently monitor the whole development of children in your care?' were coded to the appropriate listed method when possible or to 'other.' ${ }^{1}$ Text responses to the question 'Where could you refer a child if you're concerned about some aspect of the child's whole development' were coded to either 'doctor,' 'Part C/Part B,' 'other,' or 'unclear'; only findings related to the categories of doctor and Part $\mathrm{C} /$ Part B are included here. The category of doctor captures all text responses that could clearly be identified as a child's primary health care provider. The category of Part C/Part B captures all text responses that could clearly be identified as Part C or Part B services. An internet search was run for specific program or service names listed in the text response, in conjunction with the respondents' state as identified by the respondent, to clarify as many entries as possible. For example, it was common for respondents to list the Part C program name (e.g., 'First Steps' in Indiana and 'Birth to 3' in Wisconsin). Coding at multiple categories was possible. All coding was carried out by two members of the study team using consensus coding based on a coding guide. 


\section{Results}

\section{Tracking Development}

At baseline, $85.94 \%$ of respondents indicate that they track the whole development of children in their care. ECEPs in home-based programs are the least likely to report tracking at baseline ( $\mathrm{n}=384$; see Figure 1). Among those who report tracking development, the most frequently reported forms of tracking across program types are to observe development, share observations with parents, and ask parents what they observe (see Figure 2). Nearly $59 \%$ of those who report tracking development use a checklist, however, using an objective checklist and using a portfolio to document development are the least commonly used forms of tracking across program types $(n=330$; see Figure 2).

Nearly $92 \%$ of respondents indicate it is important to track the whole development of every child using an objective checklist, with little variation by program type $(n=372)$. However, only $60.41 \%$ of those who view it as important to use a checklist indicate doing so $(n=341)$. Among only those respondents who report tracking, $69.59 \%$ of those who view it as important to use a checklist indicate doing so. Use of a checklist among those who view it as important varied by program, with HS/EHS respondents most likely and Ministry least likely (see Figure 3). Checklists were also used by $45.16 \%$ of those who did not consider it important.

Of the 32 respondents who indicate they do not believe it's important to use an objective checklist, 24 provided narrative responses to the questions 'why or why not?' Responses were coded for content reflecting the acceptability (14 responses), feasibility (4 responses), and effectiveness (13 responses) of using LTSAE for developmental monitoring in childcare settings. Responses were coded at all relevant themes. Responses are summarized below, from least to most commonly coded theme, and 
characteristic responses for each theme are provided in Table 2. Responses coded to feasibility indicate that the practicality of using a checklist is impeded by time constraints, the need to document development in other ways, and the perceived impracticality of observing all milestones. Thirteen responses coded to the theme of effectiveness reflected beliefs that checklists are not accurate ( 5 responses), a checklist may be a useful guide but is not sufficient on its own (4 responses), and checklists don't add value for all children (3 responses). Responses coded to acceptability reflect beliefs that checklists do not capture the complex uniqueness of each child's development (7 responses), and that checklists are not the way that ECEPs monitor development (7 responses).

\section{Making Referrals}

When asked where they could refer when there is a concern about a child's development, over $15 \%$ of respondents indicate they do not know where to refer $(\mathrm{n}=384)$. When continuing on to list referrals, $19.62 \%$ do not list either the child's doctor or Part C/Part B as a possible referral, 72.47\% list Part C/Part B, and 32.59\% list the child's doctor $(n=316)$. Only $24.68 \%$ list both the doctor and Part C/Part B.

Demonstrated knowledge of referral to the doctor and Part C/Part B varied by program type, with HS/EHS (80.36\%) and centre-based (83.43\%) respondents more likely than home-based (66.67\%), and Ministry (62.50\%) to demonstrate knowledge of at least one of these recommended referrals $(n=316$; see Figure 4$)$. The trend toward respondents demonstrating knowledge of referral to Part C/Part B more frequently than to the doctor is evident across programs types, with the variability in knowledge of referral by program type higher for doctor than for Part C/Part B (see Figure 4).

Knowledge of referral to the doctor when there is a concern was also assessed by asking 'When is it important for a child's family to consult with the child's doctor 
about how the child is developing?', thereby prompting respondents to consider the role of the doctor. Given this prompt, $63.80 \%$ of respondents indicate parents should talk to the doctor when there is a developmental concern $(n=384)$. When both the prompted and unprompted questions relating to referral to the doctor are taken into account, a total of $71.88 \%$ respondents are able to identify the doctor as an appropriate referral when there is a developmental concern $(n=384)$.

Nearly $88 \%$ of respondents express the attitude that it is part of their professional role to refer to the child's doctor when there is a concern about development ( $\mathrm{n}=370)$. However, only $29.34 \%$ of those who view referral to the child's doctor as part of their role also demonstrate knowledge of referral to the doctor when asked where they could refer if concerned about a child development $(n=324)$. However, when responding to the question 'When is it important for a child's family to consult with the child's doctor about how the child is developing?' an additional $45.06 \%$ of those viewing it as their role did mention concern about child development as a reason to talk to the doctor. In total, $74.38 \%$ of those who view referral to the child's doctor as part of their role demonstrate knowledge of referral to the doctor, however, many of them only did so when specifically prompted to think about the role of the doctor.

\section{Discussion and Implications}

While the results reported here suggest that ECEPs attitudes, knowledge, and practice are supportive of developmental monitoring, there are gaps that may limit the effectiveness of early detection of developmental disability and appropriate referrals. First, although the majority of ECEPs in this study indicate they track the development of children in their care, forms of tracking that require documentation and/or an objective list of milestones (i.e., use of a portfolio and an objective checklist) are the 
least commonly used. Observational strategies for tracking development and discussing observations with parents may support quality early care and education and are a component of effective early identification, however, findings in the context of primary health care suggest that informal tracking methods - that is, those that rely on individual impressions and bypass use of research-based tools - fall short in reliably identifying children at risk of developmental disability (Glascoe, 2000). If these findings hold true in the context of childcare, developmental monitoring using tools that support objective tracking of a child's milestones against age norms (i.e., an objective checklist and/or developmental screening using a standardized, validated tool) may be critical to identifying children at risk for developmental disability in childcare settings. Increased use of an objective checklist may support more reliable identification of developmental concern, particularly in childcare settings in which developmental screening is not conducted.

In addition, this study found that once concern is identified, many ECEPs do not know the appropriate referrals to make. Although the majority of ECEPs demonstrate knowledge of at least some referrals that could be made, 1 out of 6 indicate they do not know anywhere to refer when there is a concern about a child's development. Among those who name a place to refer, about 7 out of 10 identify Part C/Part B as a possible referral, 1 in 3 identify the child's doctor, and less than 1 in 4 identify both Part C/Part $\mathrm{B}$ and the doctor. Familiarity with referral to Part C/Part B is an encouraging finding, since ECEPs can play an important role in an informed referral network for Child Find. However, it notable that ECEPs are far less able to demonstrate knowledge of referral to child's doctor, unless they are prompted to think about the role of the doctor. When ECEPs are prompted to consider the role of the doctor, demonstrated knowledge of the child's doctor as an appropriate referral when there is a developmental concern 
increases to about 7 out of 10, making it comparable to demonstrated knowledge of Part C/Part B. According to best practice guidelines, as well as LTSAE resources, children with a developmental concern should be referred to the child's doctor as well as to Part C/Part B. To increase early identification, diagnosis or rule out of developmental disability, and access to intervention, it is critical that ECEPs know where to refer and feel able to make referrals. Though not sufficient in itself, knowledge is nonetheless a necessary precursor to appropriate referrals being made and pursued. Improved knowledge and comfort referring to the child's doctor when there is a developmental concern may improve the capacity of ECEPs to serve a role in early detection and access to intervention for children with developmental disabilities.

Although the sample size in this study does not permit strong conclusions about differences across program types, data suggest there may be a pattern of difference in tracking, use of a checklist, and knowledge of referrals. Namely, ECEPS in HS/EHS are the most likely and home-based ECEPs the least likely to report tracking development, ECEPs in registered but unregulated ministry showed the greatest tendency toward using informal tracking methods, and ministry and home-based ECEPs were the most likely to not be able to demonstrate knowledge of referrals. Developmental monitoring training and resources may be most valuable to ECEPs in programs with lower knowledge and/or engagement in monitoring.

Findings from this study suggest that ECEPs' attitudes about components of developmental monitoring are not a good indication of practice. For example, while many ECEPs express the attitude that it's important to track development with an objective checklist, it is common for these ECEPs to not use a checklist, even when they are otherwise engaged in tracking development. It is possible that some of these ECEPs could not easily access checklists, and that improved availability of LTSAE milestone 
checklists may make it more likely for them to use checklists in the future. However, it also likely that program policy determines developmental monitoring practice. In support of this view, $45 \%$ of ECEPs who do not view it as important to track using a checklist nonetheless report using one to track development of the children in their care.

To the extent that ECEP attitudes do shape practice, it is worthwhile to understand barriers to acceptability of using an objective checklist. While feasibility was mentioned as a reason to not use a checklist, the most commonly given reason was that children are unique and develop at their own pace - a reality that is not captured by a checklist. ECEPs also felt that there are many other ways to track development, or that ECEPs monitor development differently. Because LTSAE materials were developed as a health education campaign, it is worth giving increased consideration to how well the purposes and methods of developmental monitoring using LTSAE fit into the 'culture' of early care and education. Better understanding of this issue can provide valuable insight into what modified or additional resources would best support ECEPs to play an active role in identifying children at risk for developmental disabilities early.

Findings from this study also highlight the need for increased consideration of the relationships between ECEP attitudes, knowledge, and practice. First, there is a large discrepancy between attitude and demonstrated knowledge in relation to both using a checklist and referring to the child's doctor. This suggests that studies of early detection should be cautious about drawing conclusions about developmental monitoring practice from measures of attitude. Second, there is also a large difference in demonstrated knowledge of referral to the doctor between questions that did and did not prompt to consider the doctor's role. Although it is not possible from this study to know how often ECEPs actually refer to the doctor when there is developmental concern, it is clear that assessing their knowledge of referral is impacted significantly by question 
wording. Finally, ECEPs' attitude about the importance of using an objective checklist were not highly correlated with use of a checklist in practice $(\varphi=.06)$. In the context of centre-based childcare provision, especially in HS/EHS, the capacity of individual ECEPs' attitudes and knowledge to shape developmental practice will be constrained by program policy.

\section{Limitations and Future Directions}

An important limitation of this study is that the sample is both small and is not representative of the population of childcare providers. Because this study was conducted as a program evaluation to assess the acceptability, feasibility, and effectiveness of LTSAE (including the LTSAE 'Watch Me!' training) in childcare settings, baseline data were collected from ECEPs prior to completing the CDC's 'Watch Me!' developmental monitoring training. Respondents either sought this training because of either individual interest or program-wide implementation. Therefore responses may not reflect the attitudes, knowledge, and practice of ECEPs with little to no interest in developmental monitoring. An accurate understanding of ECEPs' attitudes, knowledge, and practice related to developmental monitoring would require a study utilizing a representative sample of ECEPs.

Early detection and intervention for developmental disabilities may be most effective when a range of early childhood professionals contribute to developmental monitoring and screening, particularly since universal developmental monitoring and developmental screening are not uniformly adopted in paediatric primary care.

Although it is reasonable to assume participation by early childhood professionals will improve early detection and referral for intervention, this is an under-investigated area. Further study is needed to determine the impact of developmental monitoring in childcare settings on identification of concern, referrals made, and follow up on 
referrals by families. Further study is also needed to understand how developmental monitoring for the purpose of detecting developmental disabilities and making referrals can best be integrated into childcare settings in which development is routinely tracked for other purposes (e.g., individualizing instruction), using different processes (e.g., informal observation and portfolios of children's work), and based on values that may conflict with available tools (e.g., honouring the unique development of each child as opposed to tracking milestones against normative data). Moreover, attention should be given to how developmental monitoring processes and outcomes may differ across types of childcare program (e.g., HS/EHS, centre-based, home-based, others), and by type of monitoring tool (i.e., LTSAE should not be assumed to be the only or best tool). Finally, there is a need for research on how outcomes are impacted by developmental monitoring alone, developmental screening alone, or developmental monitoring and developmental screening together in childcare settings.

\section{References}

Angell, A. M., Empey, A., \& Zuckerman, K. (2018). A review of diagnosis and service disparities among children with autism from racial and ethnic minority groups in the United States. International Review of Research in Developmental Disabilities, 55, 145-180.

Bailey, D. B., Hebbeler, K., Spiker, D., Scarborough, A., Mallik, S., \& Nelson, L. (2005). Thirty-six-month outcomes for families of children who have disabilities and participated in early intervention. Pediatrics, 116(6), 1346-1352.

Baio J., Wiggins L., Christensen D. L., Maenner M. J., Daniels J., Warren Z., ... \& Dowling N. V. Prevalence of autism spectrum disorder among children aged 8 years - Autism and Developmental Disabilities Monitoring Network, 11 Sites, United States, 2014. MMWR: Morbidity and Mortality Weekly Report Surveillance Summaries 2018;67(No. SS-6):1-23.

Barger, B., Rice, C., \& Roach, A. (2018a). Socioemotional developmental surveillance in young children: monitoring and screening best identify young children that 
require mental health treatment. Child and Adolescent Mental Health 23(3), 206-213.

Barger, B., Rice, C., Wolf, R., \& Roach, A. (2018b). Better together: Developmental screening and monitoring best identify children who need early intervention. Disability and Health Journal, 11(3), 420-426.

Barger, B., Rice, C., Simmons, C. A., \& Wolf, R. (2018c). A systematic review of Part C early identification studies. Topics in Early Childhood Special Education, 38(1), 4-16.

Bloom, P. J. (2015). Blueprint for action: Achieving center-based change through staff development. $3^{\text {rd }}$ edition. Lake Forest, IL: New Horizons.

Boh, A., and Johnson, L. D. (2018) Universal screening to promote early identification of developmental delays: Exploring childcare providers beliefs and practices. Early Child Development and Care, 188(12), 1694-1708.

Boyle, C. A., Boulet, S., Schieve, L. A., Cohen, R. A., Blumberg, S. J., YearginAllsopp, ... \& Kogan, M. D. (2011). Trends in the prevalence of developmental disabilities in US children, 1997-2008. Pediatrics, 127(6), 1034-1042.

Branson, D., \& Bingham, A. (2017). Child care providers' competence and confidence in referring children at risk for developmental delays. Infants \& Young Children, 30, 41-57.

Branson, D., Vigil, D. C., \& Bingham, A. (2008). Community childcare providers' role in the early detection of autism spectrum disorders. Early Childhood Education Journal, 35(6), 523-530.

Burt, J. D. (2013). An Evaluation of the Milestone Moments Booklet and Interactive Milestone Checklist with Child Care Providers. Omaha, NE: Munroe Meyer Institute at the University of Nebraska Medical Center.

Campbell, J.M., Greenberg, D., Gallagher, P.A., Stoneman, Z, Simmons, C. (2018). Knowledge of autism for parents of low income with low literacy: Description and relationship to child development knowledge. Advances in Neurodevelopmental Disorders, 3(1), 8-16.

Chödrön, G., Ershler, J., Pizur-Barnekow, K., Viehweg, S., Barger, B., Puk-Ament, A. (2017). Evaluation of developmental monitoring using 'Learn the Signs. Act Early. 'in childcare settings. Madison, WI: Waisman Center University Center for Excellence in Developmental Disabilities. 
Chödrön, G., Barger, B., Pizur-Barnekow, K., Viehweg, S., Puk-Ament, A. (2019). Impact of 'Watch Me!' training on childcare providers' knowledge and attitudes related to developmental monitoring. Manuscript in preparation.

Crimmins, D., Graybill, E. C., \& Vinoski, E. R. (2013). Creative ways to reach hard to reach populations - part 1 of 2: addressing disparities in 'Learn the Signs. Act Early.', Act Early Forum Webinar Series, Association of University Centers on Disability. Retrieved from https://aucd.adobeconnect.com/_a1005431686/ltsae_reach/.

Dawson, G. (2008). Early behavioral intervention, brain plasticity, and the prevention of autism spectrum disorder. Development and Psychopathology, 20(3), 775-803.

Durkin, M. S., Maenner, M. J., Baio, J., Christensen, D., Daniels, J., Fitzgerald, R., ... \& Yeargin-Allsopp, M. (2017). Autism spectrum disorder among US children (2002-2010): Socioeconomic, racial and ethnic disparities. Journal of Public Health, 107, 1818-1826.

Early Childhood Technical Assistance Center (n.d.). Part C Infant and Toddler Program Federal Appropriations and National Child Count 1987-2016. Retrieved July 1, 2017 from http://ectacenter.org/partc/partcdata.asp.

Feinberg, E., Silverstein, M., Donahue, S., \& Bliss, R. (2011). The impact of race on participation in Part C early intervention services. Journal of Developmental and Behavioral Pediatrics, 32(4), 284.

French, L., \& Kennedy, E. M. M. (2018). Annual research review: Early intervention for infants and young children with, or at-risk of, autism spectrum disorder: a systematic review. The Journal of Child Psychology and Psychiatry, 59(4), 444456.

Glascoe, F. P. (2000). Evidence-based approach to developmental and behavioural surveilane using parents' concerns. Child: Care, Health and Development, 26(2), 137-149.

Graybill, E., Self-Brown, S., Lai, B., Vinoski, E., McGill, T., \& Crimmins, D. (2016). Addressing disparities in parent education: Examining the effects of Learn the Signs/Act Early parent education materials on parent outcomes. Early Childhood Education Journal, 44(1), 31-38.

Guevara, J. P., Gerdes, M., Localio, R., Huang, Y. V., Pinto-Martin, J., Minkovitz, C. S., ... \& Pati, S. (2013). Effectiveness of developmental screening in an urban setting. Pediatrics, 131(1), 30-37. 
Guerrero, A. D., Rodriguez, M.A., \& Flores, G. (2011). Disparities in provider elicitation of parents' developmental concerns for US children. Pediatrics, 128(5), 901-909.

Hagan, J. F., Shaw, J. S., Duncan, P. M. (2017). Bright F=futures: Guidelines for health supervision of infants, children, and adolescents. 4th edition. Elk Grove, IL: American Academy of Pediatrics.

Hebbeler, K., Spiker, D., Bailey, D., Scarborough, A., Mallik, S., Simeonsson, R., \& Nelson, L. (2007). Early intervention for infants and toddlers with disabilities and their families: Participants, services, and outcomes. Menlo Park, CA: SRI International.

Hirai, A. H., Kogan, M. D., Kandasamy, V., Reuland, C., Bethell, C. (2018). Prevalence and variation of developmental screening and surveillance in early childhood. JAMA: Journal of the American Medical Association Pediatrics, 172(9), 857866.

Landa, R. J., \& Kalb, L. G. (2012). Long-term outcomes of toddlers with autism spectrum disorders exposed to short-term intervention. Pediatrics, 130(Supplement 2), S186-S190.

Macy, M., Marks, K., \& Towle, A. (2014). Missed, misused, or mismanaged: improving early detection systems to optimize child outcomes. Topics in Early Childhood Special Education, 34(2), 94-105.

Mandell, D. S., Wiggins, L. D., Carpenter, L. A., Daniels, J., DiGuiseppi, C., Durkin, M. S., ... \& Kirby, R. S. (2009). Racial/ethnic disparities in the identification of children with autism spectrum disorders. American Journal of Public Health, 99(3), 493-498.

Meisels, S. J. \& Atkins-Burnett (2005). Developmental screening in early childhood: a guide, $5^{\text {th }}$ edition. Washington, DC: National Association for the Education of Young Children.

Morgan, Paul L., Farkas, G., Hillemeier, M. M., \& Maczuga, S. (2012). Are minority children disproportionately represented in early intervention and early childhood special education? Educational Researcher, 41(9), 339-351.

National Association for the Education of Young Children (2018). NAEYC Early Learning Program Accreditation Standards and Assessment Items. Washington, DC: National Association for the Education of Young Children. Retrieved from https://www.naeyc.org/sites/default/files/globally- 
shared/downloads/PDFs/accreditation/early-

learning/standards and assessment web 0.pdf.

National Association for the Education of Young Children (2009). NAEYC standards for early childhood professional preparation: A position statement of the National Association for the Education of Young Children. Washington, DC: National Association for the Education of Young Children. Retrieved from https://www.naeyc.org/resources/position-statements/standards-professionalpreparation.

National Survey of Early Care and Education Project Team. (2013). Number and characteristics of early care and education (ECE) teachers and caregivers: Initial findings from the national survey of early care and education (NSECE). OPRE Report \#2013-38, Washington DC: Office of Planning, Research and Evaluation, Administration for Children and Families, U.S. Department of Health and Human Services.

Patel, K. P. (2007). The impact of the 'Learn the Signs. Act Early.' public health awareness campaign on early intervention behavior (Master's thesis), Georgia State University, Atlanta, GA. Retrieved from https://scholarworks.gsu.edu/iph theses/3/.

Pizur-Barnekow, K, Erickson, S., Johnston, M., Bass, T., Lucinski, L., Bleuel, D. (2010). Early identification of developmental delays through surveillance, screening, and diagnostic evaluation. Infants \& Young Children, 23(4), 232-330.

Raspa, M., Levis, D. M., Kish-Doto, J., Wallace, I., Rice, C., Barger, B., ..., \& Wolf, R. B. (2015). Examining parents' experiences and information needs regarding early identification of developmental delays: Qualitative research to inform a public health campaign. Journal of Developmental \& Behavioral Pediatrics, 36(8), 575-585.

Reichow, B., Hume, K., Barton, E. E., \& Boyd, B.A. (2018). Early intensive behavioral intervention (EIBI) for young children with autism spectrum disorders (ASD). Cochrane Database of Systematic Reviews, 5. Art. No.: CD009260.

Rogers, S. J., Estes, A., Lord, C., Vismara, L., Winter, J., Fitzpatrick, A., ..., \& Dawson, G. (2012). Effects of a brief Early Start Denver Model (ESDM)-based parent intervention on toddlers at risk for autism spectrum disorders: A randomized controlled trial. Journal of the American Academy of Child \& Adolescent Psychiatry, 51(10), 1052-1065. 
Rogers, S. J., Estes, A., Lord, C., Munson, J., Rocha, M., Winter, J., .. \& Talbott, M. (2019). A multisite randomized controlled two-phase trial of the Early Start Denver Model compared to treatment as usual. Journal of the American Academy of Child \& Adolescent Psychiatry. Advance online publication. doi: 10.1016/j.jaac.2019.01.004.

Rosenberg, S. A., Zhang, D., \& Robinson, C. C. (2008). Prevalence of developmental delays and participation in early intervention services for young children. Pediatrics, 121(6), e1503-e1509.

U.S. Census Bureau (2018). QuickFacts United States. Retrieved from https://www.census.gov/quickfacts/fact/table/US.

U.S. Department of Health and Human Services \& U.S. Department of Education (2014). Birth to 5: Watch me Thrive!: An early care and education provider's guide for developmental and behavioural screening. Retrieved from https://www.acf.hhs.gov/sites/default/files/ecd/ece_providers_guide_march2014 .pdf.

Westat. (2015). Is Amazing Me! amazingly impactful in pediatric settings? Rockville, MD: Westat. Evaluation study findings shared with authors by the Act Early team, National Center for Birth Defects and Developmental Disabilities, Centers for Disease Control and Prevention.

Zwaigenbaum, L., Bryson, S., Rogers, T., Roberts, W., Brian, J., \& Szatmari, P. (2005). Behavioral manifestations of autism in the first year of life. International Journal of Developmental Neuroscience, 23(2-3), 143-152. 
Table 1. Participants by Study Arm, Type of Program, and Role

\begin{tabular}{|l|l|l|l|}
\hline \multirow{2}{*}{ Type of Program } & Number of Respondents & \multicolumn{2}{l|}{} \\
\cline { 2 - 5 } & Training-only & Training+TA & $\begin{array}{l}\text { Total } \\
\text { (\% of total) }\end{array}$ \\
\hline Head Start/Early Head Start & 61 & 0 & $61 \quad(15.89 \%)$ \\
\hline Centre-Based & 149 & 77 & $226 \quad(58.85 \%)$ \\
\hline Home-Based & 52 & 5 & $57 \quad(14.84 \%)$ \\
\hline Ministry & 0 & 13 & $13 \quad(03.39 \%)$ \\
\hline Other/unknown & 25 & 2 & $27 \quad(07.03 \%)$ \\
\hline $\begin{array}{l}\text { Respondent Role } \\
\text { Direct care provider } \\
\text { (with or without other roles) }\end{array}$ & Training-only & Training+TA & $\begin{array}{l}\text { Total } \\
(\% \text { of total) }\end{array}$ \\
\hline $\begin{array}{l}\text { Director/Owner/Administrator } \\
\text { (excluding direct care) }\end{array}$ & 112 & 85 & $260 \quad(67.71 \%)$ \\
\hline
\end{tabular}


Table 2. ECEPs' Reasons for Believing 'Use of Checklist' Is Not Important

\begin{tabular}{|c|c|}
\hline $\begin{array}{l}\text { Theme (Total } \\
\text { responses) }\end{array}$ & Representative responses \\
\hline $\begin{array}{l}\text { Acceptability: } \\
\text { Children are } \\
\text { unique ( } 7)\end{array}$ & $\begin{array}{l}\text { - 'most are developing just fine! We all develop at different rates, } \\
\text { - 'e all work on different areas at different times!' } \\
\text { - 'every child is different and may develop at his or her own pace' }\end{array}$ \\
\hline $\begin{array}{l}\text { Acceptability: } \\
\text { Not the way } \\
\text { ECEPs monitor } \\
\text { development } \\
\text { (7) }\end{array}$ & $\begin{array}{l}\text { - 'observing children without a list will provide a more accurate } \\
\text { depiction of each child because you can write open ended } \\
\text { statements about each individual child rather than trying to find a } \\
\text { standard that fits the behaviours they are exhibiting. [I] feel like } \\
\text { you are getting to know the child better by doing this as well' } \\
\text { - 'I don't think one tool can cover everything you need... so you } \\
\text { work with the child at the level they are at and you scaffold their } \\
\text { learning according to their individual needs' }\end{array}$ \\
\hline Feasibility (4) & $\begin{array}{l}\text { - 'I think it is important to be realistic about the amount of time } \\
\text { childcare providers have to devote to paperwork' } \\
\text { - 'We would need to keep record in diff[e]rent ways' }\end{array}$ \\
\hline $\begin{array}{l}\text { Effectiveness: } \\
\text { Not accurate (5) }\end{array}$ & $\begin{array}{l}\text { - 'does not provide an accurate account' } \\
\text { - 'may miss the real development....subjective' }\end{array}$ \\
\hline $\begin{array}{l}\text { Effectiveness: } \\
\text { Not sufficient } \\
\text { (4) }\end{array}$ & $\begin{array}{l}\text { - 'should be considered more of a guideline than the rule' } \\
\text { - 'it is good to use a combination of checklists, observations, parent } \\
\text { reports, assessments' }\end{array}$ \\
\hline $\begin{array}{l}\text { Effectiveness: } \\
\text { No added value } \\
\text { (3) }\end{array}$ & $\begin{array}{l}\text { - 'there are many ways to keep track of developments without using } \\
\text { checklists' } \\
\text { - 'developmental scre[e]nings can find issues that a parent may not } \\
\text { recognize' }\end{array}$ \\
\hline
\end{tabular}


Figure 1. Percentage of ECEPs Who Report Tracking Development by Program Type

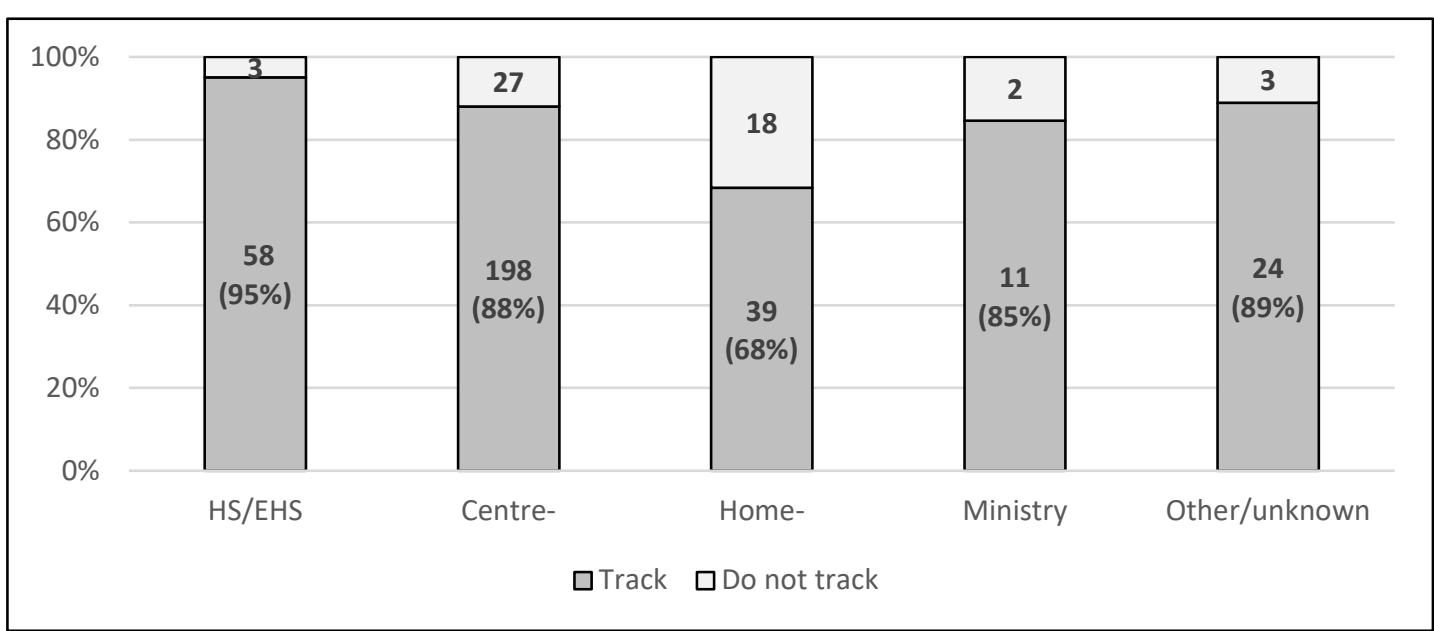


Figure 2. Percentage of ECEPs Using Forms of Tracking by Program Type

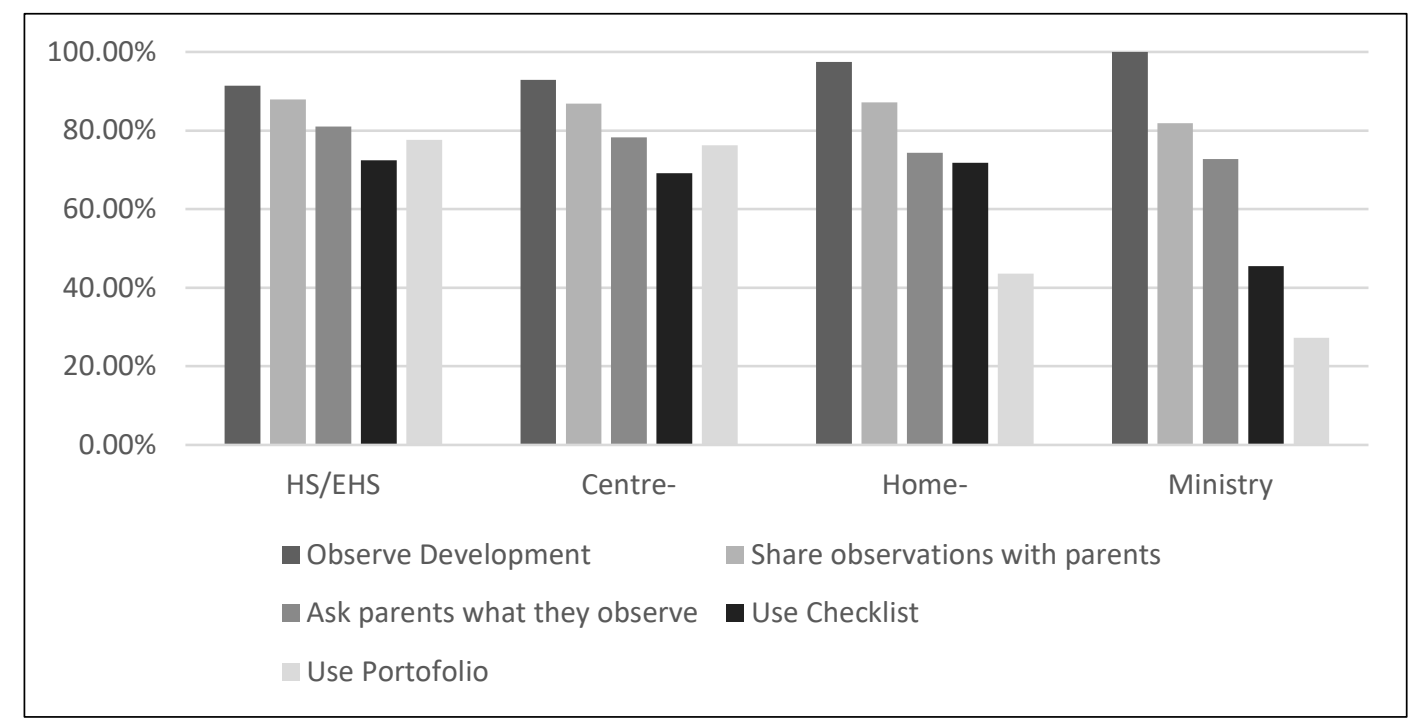


Figure 3. Use of Checklist to Track Development Amongst ECEPs Who Report it is Important to Use an Objective Checklist by Program Type

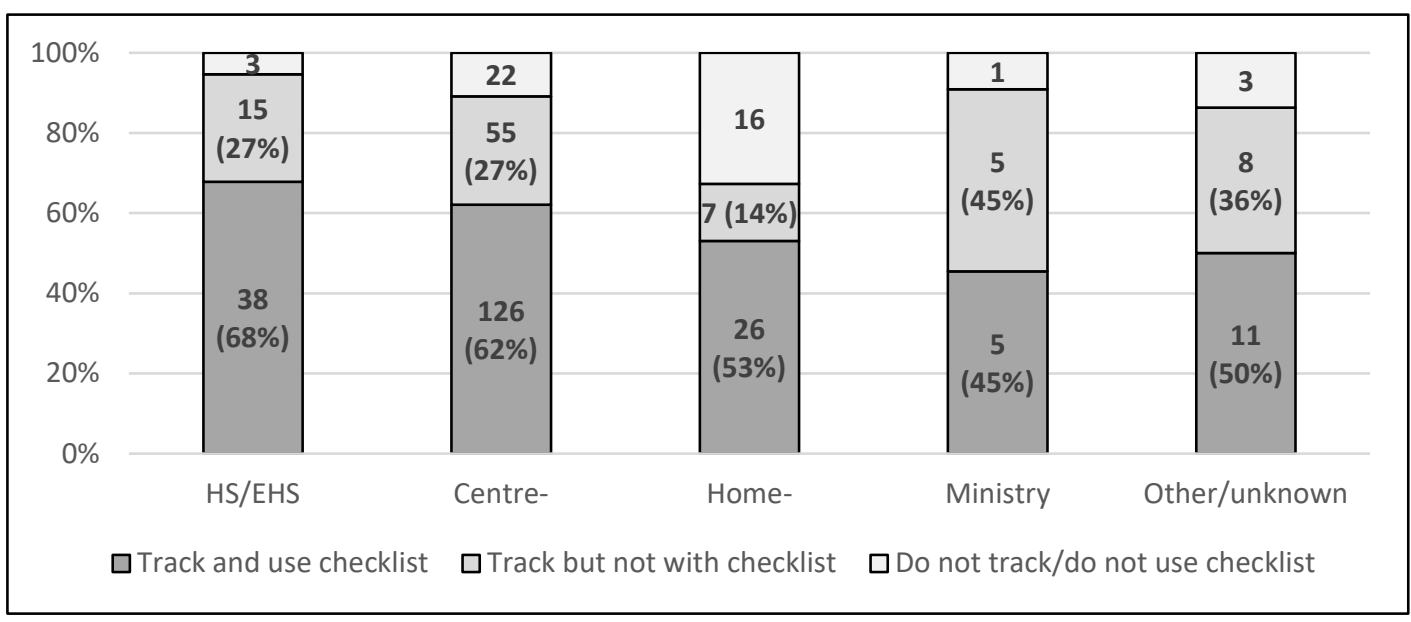


Figure 4. Percentage of ECEPs Demonstrating Knowledge of Referral to Doctor and Part C/Part B by Program Type

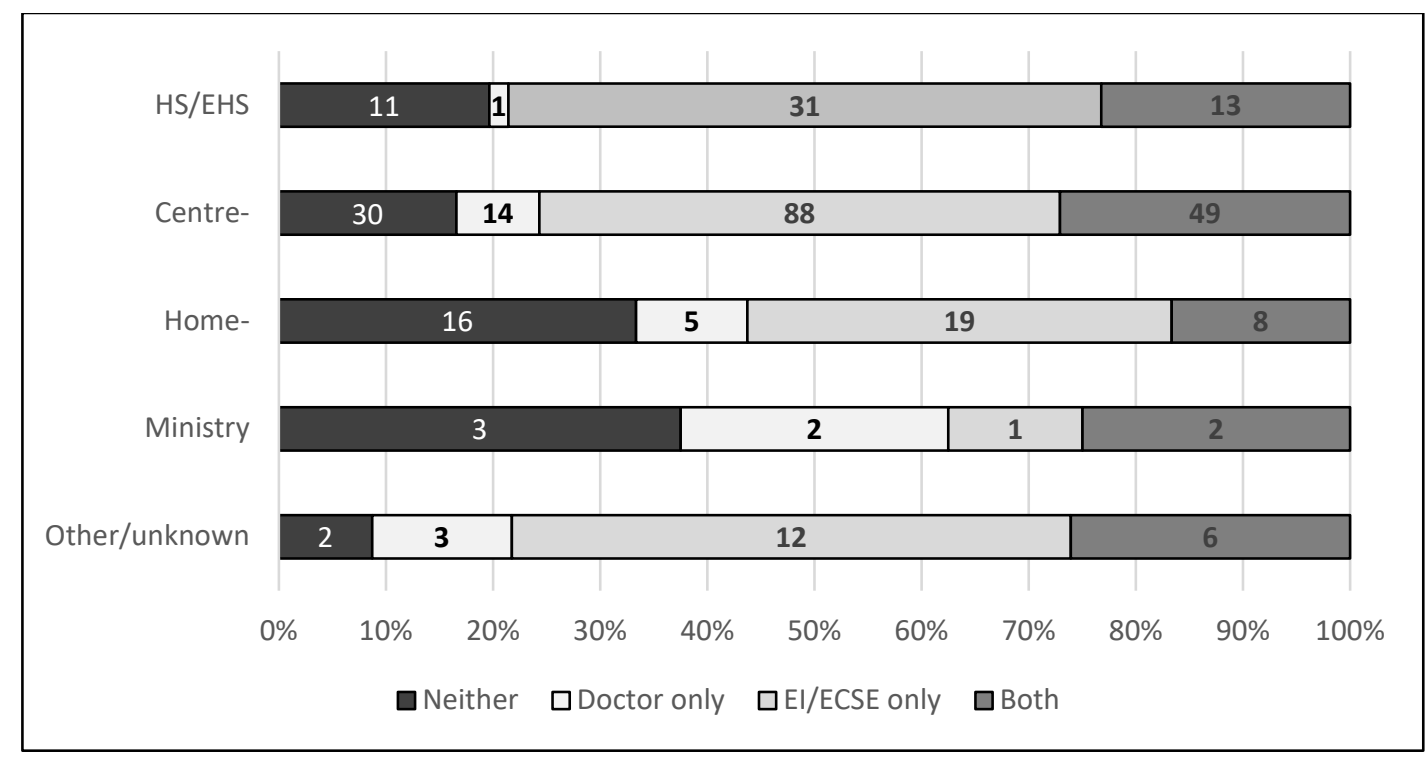

